\title{
TPM-based Focused Breakdown Reduction Strategy in Industry
}

\author{
Daniel Kiptoo Arusei \\ Department of Mechanical and Production Engineeing, \\ Moi Univerity, Eldoret Kenya
}

\author{
Stephen M. Talai, Lazarus K. Limo \\ Department of Mechanical and Production Engineering, \\ Moi University, Eldoret, Kenya
}

\begin{abstract}
Current trends in many Industries is to shift from traditional maintenance methods to implementing Total Productive Maintenance (TPM Its ultimate goal is to increase reliability and availability and the way to accomplish it is through elimination of major losses; resulting from mechanical nature that are visualized by the Overall Equipment Effectiveness (OEE) tree. The main Key performance indicators for this research are; OEE, Mean Time Before Failure (MTBF), Mean Time To Repair (MTTR) and Breakdown Percentage. Therefore, this paper provides a review of the available approaches for lean-TPM implementation in industry, with specific emphasis on breakdown reduction. The gains in productivity or effectiveness were achieved only through measures in TPM, mainly the Preventive Maintenance (PM) pillar, and not harder labor. The approaches used in achieving these goals included; Autonomous maintenance, Continuous improvement, Root cause analysis for failure, Preventive maintenance among others
\end{abstract}

Keywords - Total Productive Maintenance Overall Equipment Effectiveness, Breakdown reduction, Mean Time Before Failure.

\section{INTRODUCTION}

For decades, industrial and other organizations concentrated most of their attention on production, generally ignoring the maintenance function. Recently there has been a gradual attitude change in how general corporate managers view the maintenance function (Peterson, 2013). One of the most important factors forcing this change was that maintenance departments became major cost centers within the organizations. Today with general operating costs rising at the rate of $10 \%$ each year, there is the potential for the realization of significant savings in the maintenance department that deserves serious scrutiny (Bruce, 2011).

Lean manufacturing is an approach in manufacturing that aims to improve product quality and output, reduce costs, and eliminate all possible waste. This is achieved through Total Productive Maintenance (TPM). Early automobile manufacturing had sparked the creation of lean manufacturing. John Krafcik and Taiichi Ohno had combined the necessary criteria in order to create the Toyota Production system (TPS). This combination includes the skill and knowledge with the standardization of the work involved in TPS.

Efficiency of the moving assembly line was also emphasized including the concept of teamwork. (Womack et al., 1990). The term "Lean Production System" was introduced by John Krafcik in 1998 in his review of the TPS; while Womack et al. (1990) had popularized the term of "Lean Manufacturing". Regularly, lean manufacturing is always related with benefits such as increased quality, reduced inventories, increased customer satisfaction, increased flexibility, and reduced manufacturing times (Womack and Jones, 1996; Ross and Francis, 2003; Alavi, 2003). It is difficult to convince the managers and employees to think and act in a different way. It is also difficult to manage external relationships with the suppliers and customers. Customers may be unable to place predictable orders, causing the organisation fail in preparing the inventory to meet demand. While on the suppliers' side, they may find it hard to deliver subassemblies or a small quantity of parts (Womack and Jones, 1994).

Lean production optimizes the skills of the workforce through encouraging continuous improvement activities including integrating direct and indirect work and giving workers more than one task. Therefore, manufacturing a large variety of products can be carried out with lean production.

Ireland and Dale (2001) carried out a study on three different companies to determine the effectiveness of TPM implementation in real situations. It consisted of a UK plant with a wide range of rubber products (Company A), a packaging company (Company B), and motorized vehicles manufacturing company (Company $\mathrm{C}$ ). These were selected due to differences in their background such as number of employers, machinery used, organisational structure, and strategic objectives. The differences affected the TPM method of implementation in each company.

Chan, et. al. (2005) studied an electronic manufacturing company to see whether TPM implementation is worth a move for any company. The general aim of this project was to know effectiveness and difficulties in TPM implementation.

Eti et. al (2004) focused on how manufacturing industries in Nigeria can implement TPM by researching on their problems and shortcomings with the old traditional ways of maintenance. This way, the manufacturing industries can use this recommendation and suggestion as prerequisites before implementing TPM in their company.

Friedli et al. (2010) recorded that a pharmaceutical manufacturing company increase their OEE from 36\% in 2004 to $51 \%$ in 2009. In Friedli et al. (2010) case study, the main problem was the result of direct stoppage and breakdowns in the production. This unplanned maintenance work suggests that TPM implementation was not in its full potential as the autonomous maintenance activity should reduce on this kind of losses.

Daniel Ottosson (2009), studied the initiation of TPM in a pilot line of German automobile company. The study showed 
remarkable improvements in OEE and the productivity per man hour.

\section{MAINTAINANCE PRACTICES}

There is an important goal in lean manufacturing practice which is to become highly responsive to customer demand with the production of high quality products. This goal has to be carried out in the most efficient and economical method which are by reducing various waste in inventory, human effort, manufacturing space, and time to market. To make this happen, elimination of all kind of waste is essential. Waste exists in many forms and can be spotted at any place and in any time of operations. It does not add any value to the product. On the contrary, it will only consume the resources. Total Productive Maintenance is based on a combination of the concepts of Productive Maintenance (PM), Maintenance Prevention (MP) and Maintainability Improvement (MI). This shows where it's coming from and the direction it is supposed to take. It could be explained as being Productive Maintenance with the complete involvement of all parties (Nakajima, 1995).

To understand the principle of TPM, a more detailed explanation is necessary. Nakajima uses five main points to explain TPM:

- The goal of TPM is the maximisation of overall effectiveness. This serves the purpose of achieving machines running at their intended capacity without unplanned interruptions.

- TPM establishes a system for productive maintenance during the entire lifespan of the equipment. As reason would suggest, a machine tends to break down more towards its later days. Therefore, TPM aims to continuously keep machines in good shape and even facilitate maintenance.

- Also TPM should be realized in all divisions of a company, so that Engineering, Maintenance, Management divisions as well as the workers on the shop floor pull together.

- TPM is designed to promote Productive Maintenance through motivational management in minor, autonomous groups.

A) TPM Principles

There are five major TPM principles:

1. Improving OEE by identifying possible losses of facilities and equipment, and monitoring all of them in case of speed losses, defect losses and down-time losses.

2. Making front-line asset care as a part of the job: Front-line asset care (Autonomous Maintenance) is carried out by the operator, with support from the maintenance department. The operator should be able to fulfill at least some maintenance tasks including simple repairs, preventive actions and improvements e.g. corrective actions and proposing ways to prevent drawbacks to recur.

3. Having a systematic approach towards maintenance activities; This could be done by:

i) Defining preventive maintenance for each piece of equipment (Time Based Maintenance- TBM)

ii) Creating standards for running Condition-Based Maintenance (CBM) (iii) Defining maintenance responsibilities for operators and maintenance staff

- Operators' responsibilities: General care

- Maintenance staff responsibilities: General breakdown activities, supporting operators by training them, problem diagnosis, devising and assessing maintenance practice, developing maintenance actions and continuous up grading of equipment

- In order to thoroughly fulfill their duties and perform all their tasks, the employees need to receive continuous and appropriate training to develop their abilities like hand and operational skills, team working and problem solving.

4. Early equipment management: Zero maintenance is a concept inducing that failure causes and maintainability of the equipment should be considered during early stages of equipment life span like designing, manufacturing, installation and commissioning.

Therefore, any problem can be tracked back and eliminated at the above-mentioned stages (Thomas R. Pomorski, 2004; Imants BVBA, 2009).

The principles allowing TPM to eliminate losses and maximise productivity are described in the TPM House (Fig 1). It is based on the eight pillars of TPM, defined by the Japan Institute of Plant Maintenance (JIPM)( JIPM Solutions Co., Ltd., 2009).

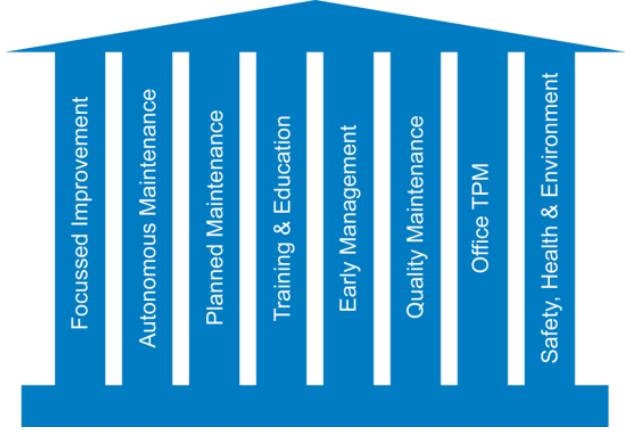

Fig. 1. The TPM House, based on the eight pillars defined by JIPM.

\section{Focused Improvement (Kobetsu Kaizen)}

This pillar states that small improvements are more effective than just one big improvement if they are continuous and encourage all employees to be involved. It aims to reduce losses that can lower efficiency. Kaizen is applicable in both production and administrative areas.

\section{Kaizen emphasis}

(i) Finding the ways of achieving zero loss in all activities (ii) Elimination of losses by means of using results of PM analysis widely

(iii) Commitment toward cost reduction for resources (iv) OEE and OPE improvements

Kaizen strives to make substantial improvements in productivity in forms of efficient equipment, operators and material in addition to energy utilization. Kaizen tries to eliminate six losses, which are described below:

(v) Equipment failure: Causes production downtime. By cooperation between the maintenance and production departments, equipment failures can be prevented by using, predictive and preventive maintenance, developing operation practices and design changes. Root Cause Failure Analysis 
(RCFA) is a technique that is used after a failure occurrence. RCFA aims to eliminate failures and mitigate their impact.

vi) Time for Setup and adjustments: It includes the time for the warming-up of a machine after its changing over.

vii) Small stops: These stops last between 5-10 minutes and include minor adjustments and cleaning.

viii) Speed losses: Several items may result in a machine working at a lower speed than what is determined before. These items can be no matching between machine and its application, inefficiency of the operator, unsuitable machine wear-parts and substandard materials.

ix) Losses during warming-up: This includes losses in a quality point of view for products produced during the time of warming-up. (J. Venkatesh, Reliabilityweb.com, 2009)

B) Overall Equipment Effectiveness (OEE)

Overall equipment effectiveness allows visualization of machine-related losses. This might seem easy at first, because with a machine theoretically able to run 24 hours a day and 365 days each year we get an amount of products representing the maximum capacity. Due to holidays and managerial decisions as not working on most weekends and so on, the maximum capacity is mostly never exploited (Reitz, 2008).

Therefore, the quotient of the actual numbers of produced units put up against the maximum capacity yields the effectiveness of the equipment during the chosen time period; the overall equipment effectiveness(Reitz, 2008). It is important to keep in mind that the OEE is only a measurement of mechanical components. Therefore all losses, even those influenced by human aspects, such as change-overs, should be considered as the only interest in the OEE is to see whether the equipment runs according to its capability (Reitz, 2008). The basic requirement for a correct calculation of the OEE is precise data. All mechanical losses need to be recorded for best results.

\section{C) General Model of OEE calculation.}

The formula for the calculation of OEE was developed by JIPM and is a factor from three different rates; namely availability, performance and quality.

Where,

$$
O E E=A R \times P R \times Q R \times 100 \%
$$

$\mathrm{AR}$ is the availability rate

$\mathrm{PR}$ - the performance rate

QR - Quality rate.

$$
A R=\frac{A T}{P P T}=\frac{P P T-D T}{P P T}
$$

AT - is the Total available time for production $=$ PPT $-\mathrm{DT}$

PPT - Planned production time

DT - Downtime loss

$P R=\frac{I C T \times P P}{A T}$

Where; ICT - Ideal cycle time, is the quickest time at which the machine could produce a single part.

PP - Total parts produced inclusive of defective

parts

$$
Q R=\frac{G P}{P P}
$$

Where; GP - Good parts produced.

\section{METHODOLOGIES FOR TPM BASED FOCUSED BREAKDOWN REDUCTION}

\section{A) Productivity Model}

The productivity model is defined in Fig. 2, capturing all machine parts, possible stops, responsibility and the owner of all stops.

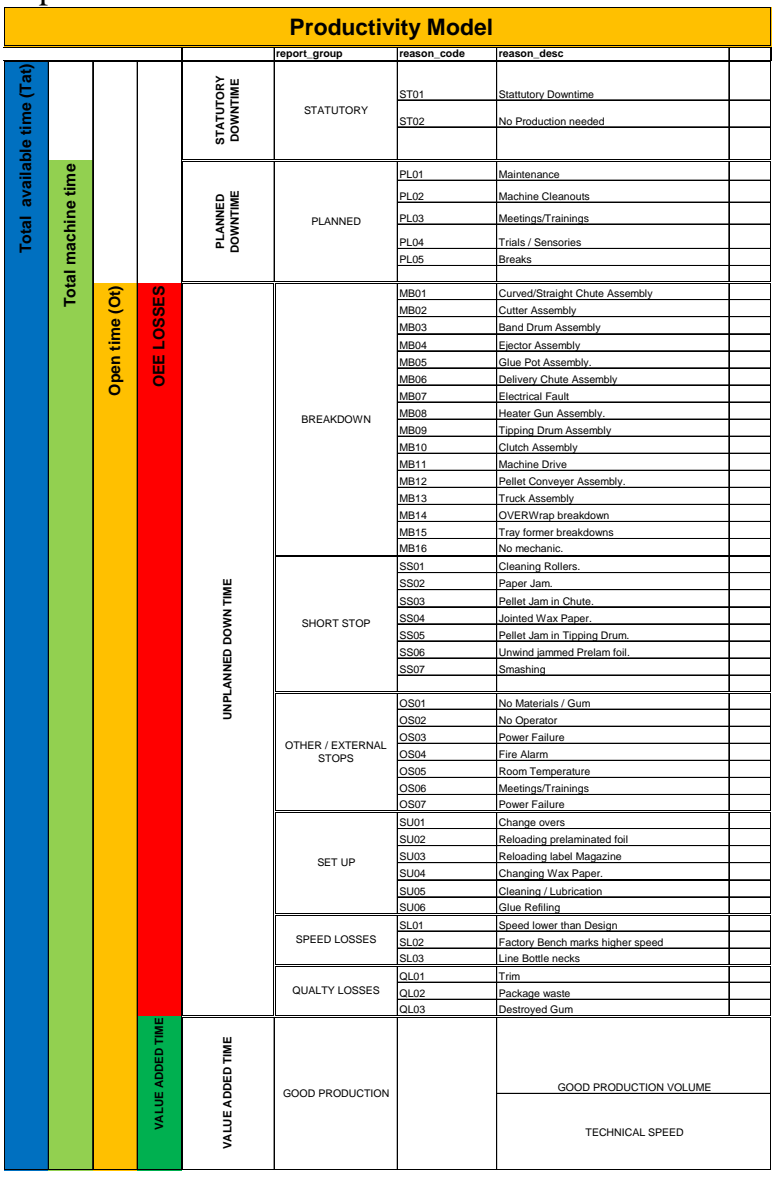

Fig. 2. Productivity Model.

\section{B) Model Description}

1. Total available time (Tat)

This refers to the total clock hours available in a shift. For example the day shift in Company $\mathrm{X}$ runs from 0800hrs to $1800 \mathrm{hrs}$, giving Tat of 10 hours, whereas night shift starts at $1800 \mathrm{hrs}$ to $0800 \mathrm{hrs}$ giving Tat of 14 hours. In this case the Total available time is equivalent to total machine time (Tmt), since there is no break between shifts.

2. Open time (Ot)

This is the total time available for production and is normally expressed as $\mathrm{Ot}=\mathrm{Tmt}$-planned losses.

3. Statutory Time.

This includes all gazetted holidays, planned offs and scheduled shutdowns.

4. Planned downtime

These are times planned into the production schedule, for example meetings, planned maintenance, machine cleanouts, breaks and trials.

5. Unplanned downtimes.

These include breakdowns, short stops, external stops (like power outages, Fire incidents, sick offs and others), Set up 
times necessitated by product change, speed losses and quality losses.

6. Value added time.

This time constitutes the total open time less planned and unplanned downtimes.

$$
\begin{aligned}
\text { C) } \text { Performance metrics. } \\
1.0 E E=\frac{\text { Vat }}{O t}
\end{aligned}
$$

2. Standard Asset Effectiveness $(\mathrm{SAE})=\mathrm{Vat} \div \mathrm{Tmt}(6)$

3. Total Asset Effectiveness $(\mathrm{TAE})=\mathrm{Vat} \div$ Tat

4. Saturation Index $=$ Tmt $\div$ Tat

5. Mean Time to Repair

MTTR was calculated using the formula shown in equation 3.5 below.

$$
\text { MTTR }=\frac{\text { Total Machine Breakdown Downtime }}{\text { Total number of breakdowns }}
$$

6. Mean Time Before Failure

MTBF was calculated using the formula shown in equation 3.6 below.

MTBF $=\frac{\text { Total Machine Production time }}{\text { Total number of breakdowns }}$

D) Breakdown reduction Master Plan

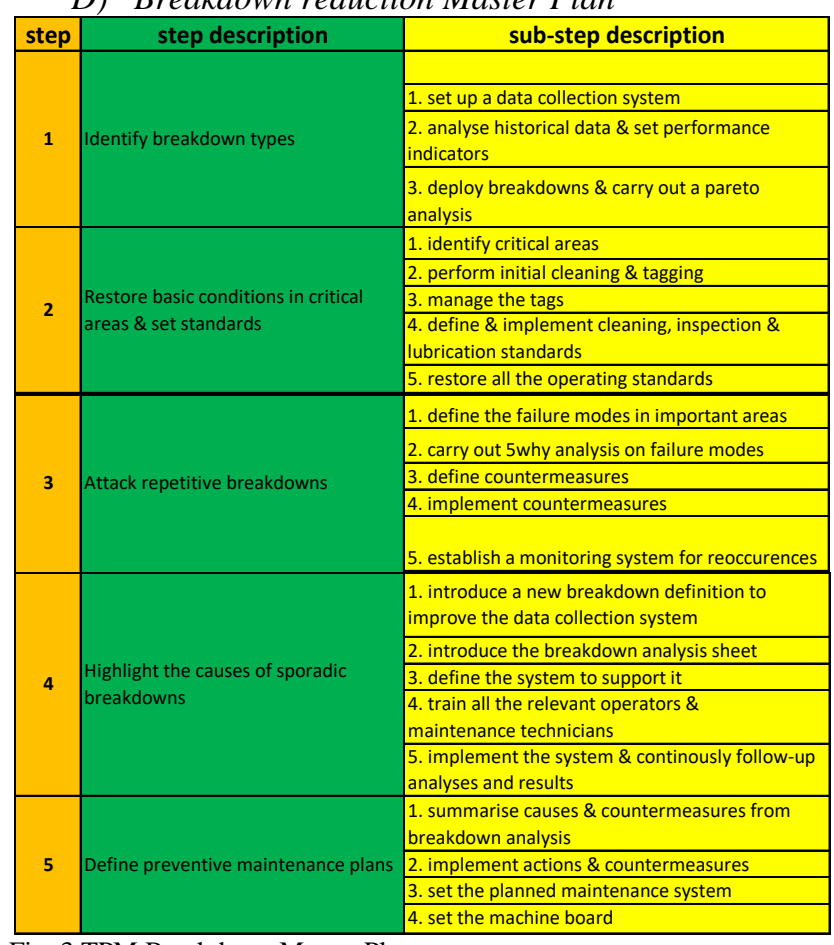

Fig. 3 TPM Breakdown Master Plan

E) Standards Developed.

(i) One point Lessons

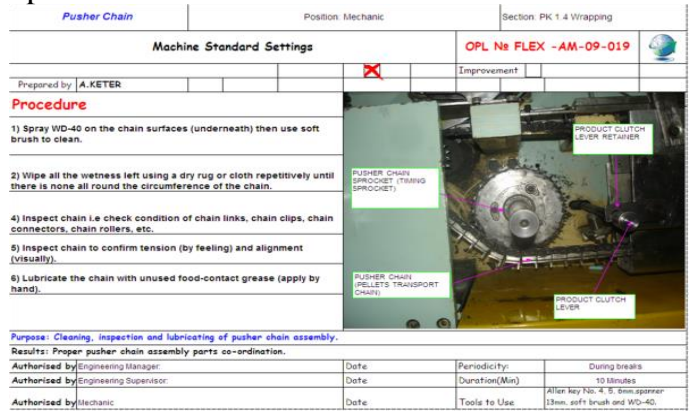

Fig. 4 One Point Lesson. (ii) Condition, Inspection and Lubrication Checklist

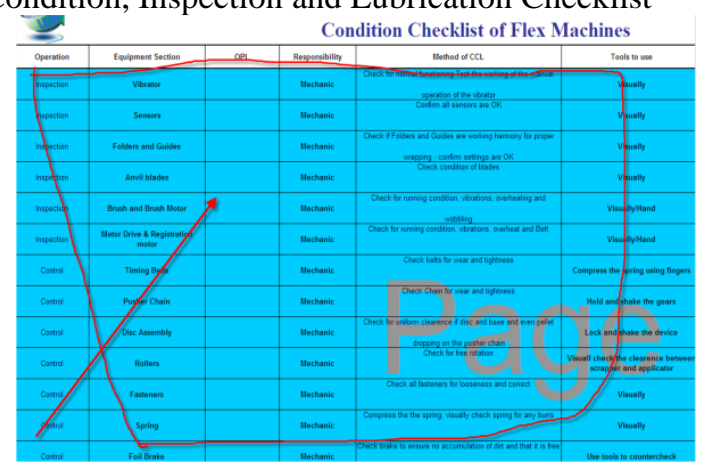

Fig. 5 Condition, Inspection and Lubrication Checklist

(iii) Spare Parts Catalogue

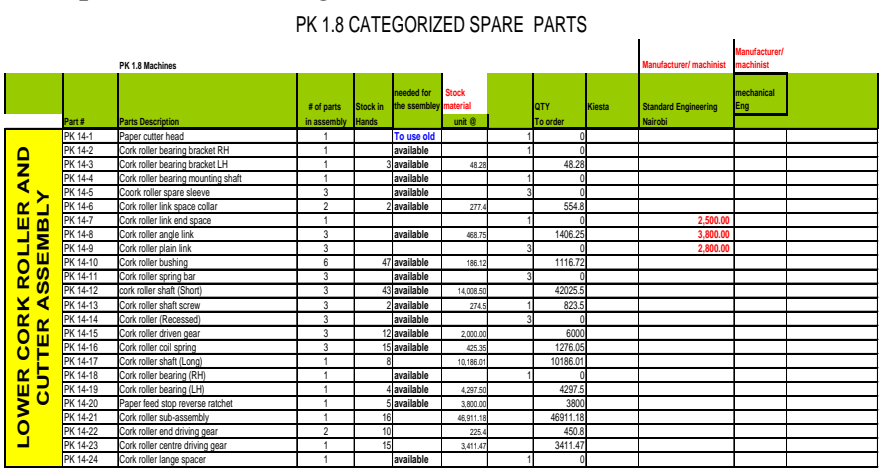

Fig. 6 Spare Parts Catalogue

(iv) Production Log Sheet.

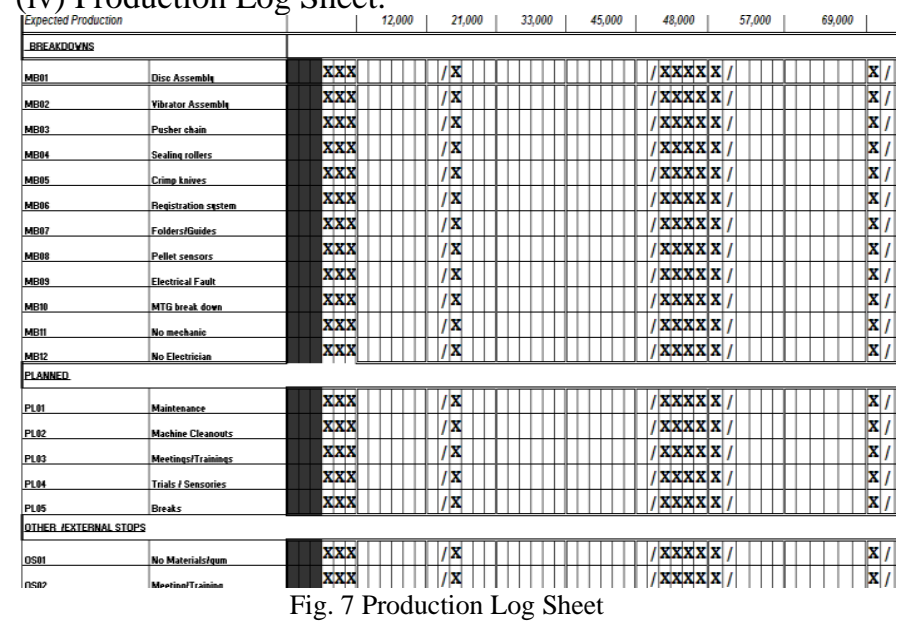

(v) Skill Gap analysis Sheet

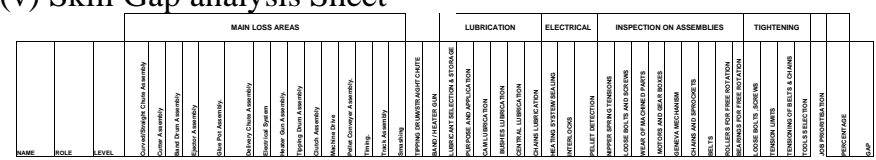

Fig.12 Skill Gap analysis Sheet

\section{RESULTS AND DISCUSSION}

The results as discussed as follows:

1. OEE Trends with Time. 


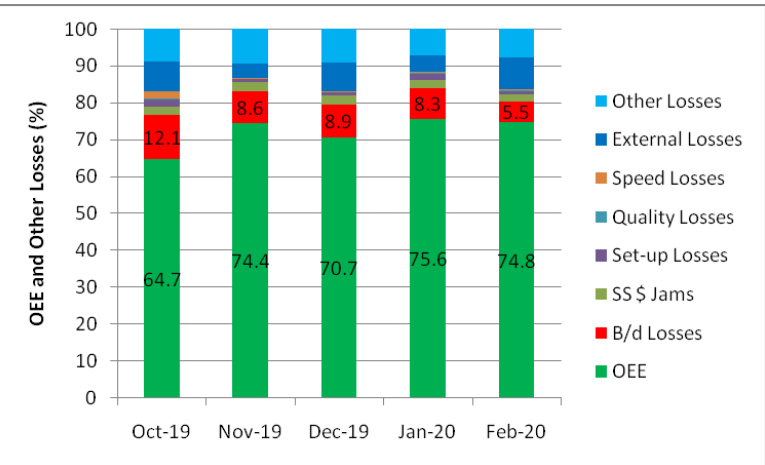

Fig. 8 OEE Tree Trends

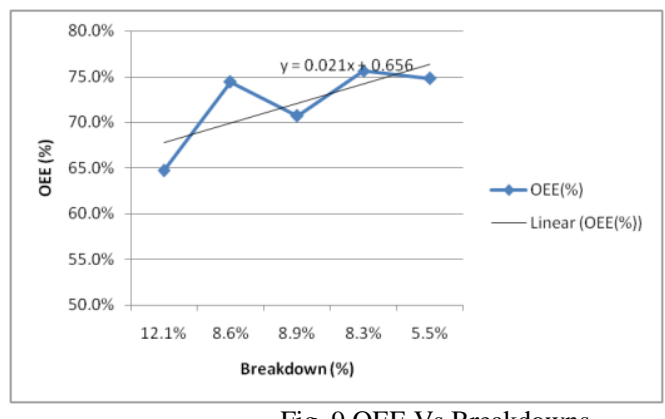

Fig. 9 OEE Vs Breakdowns

From Figure 8 we can deduce that the OEE of Wm. Wrigley Company PK Line 6 is significantly increasing from $64.7 \%$ in October to $74.8 \%$ in February. The main contributor to OEE increase was the reduction in breakdowns and Speed losses. The reduction in speed losses was attributed to the use of modular parts which ensured that the pulley running the drive was changed to match the original equipment manufacturer standards (step 2 of Master Plan).

The results herein agrees with the works of Friedli et al. (2010), point of departure being the Focused Breakdown reduction vis a vis Total TPM implementation.

\section{Variation of MTTR with Time}

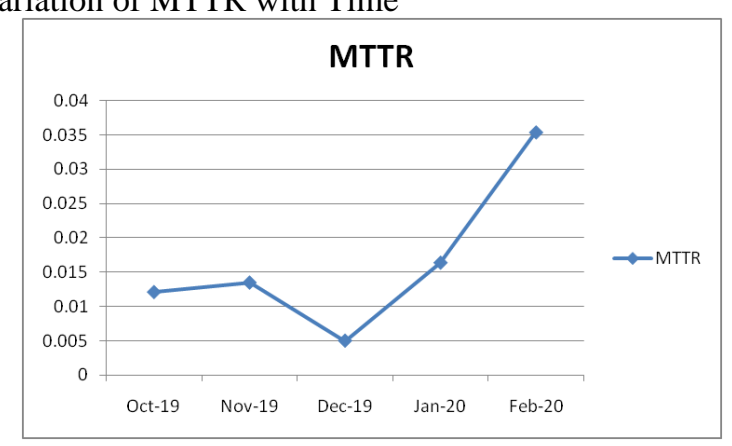

Fig. 10 MTTR Trends

The major contributors to the reduction in mean time to repair were:

(i) The re-arrangement of the spare parts store according to the movement of parts as well as cataloging parts per assembly greatly reduced the time spent by mechanics to find a part in the store (Fig. 6).

(ii) Development of one point lessons for standard setting of the major assemblies of the machine and tools to use assisted in ensuring a standard way of repair (Fig. 4). (iii) Training of both mechanics and operators on machine standards.

(iv) The Cleaning, inspection and Lubrication checklists assisted in noting possible breakdowns before hand, hence allows for time to prepare to correct the problem. Which agrees with the works of Kamran (Kamran Shahanaghi, 2009).

3. Variation of Mean time before Failure (MTBF) with time

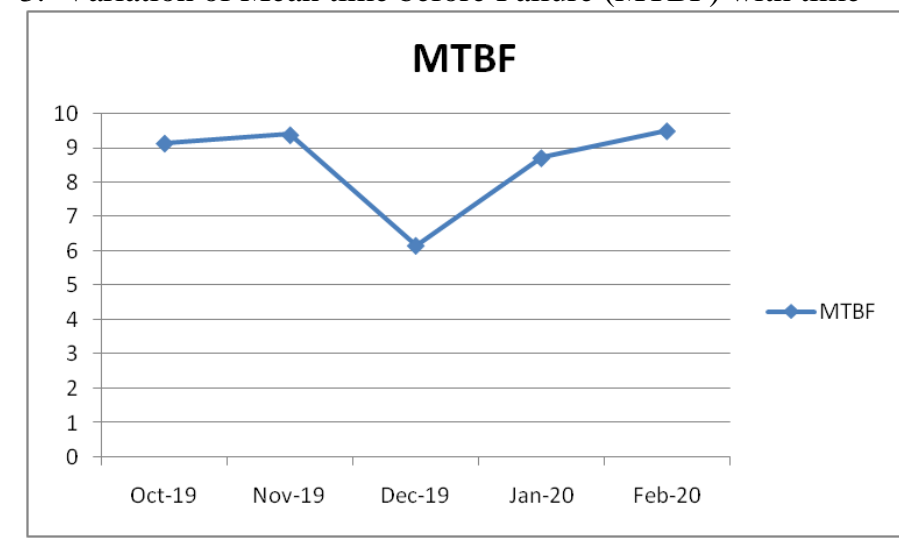

Fig. 11 MTBF variation over time.

The mean time between failures initially reduced then increased from the third month onwards. The initial reduction was attributed to the restoration of basic machine conditions in step one and two (Fig.3). This is because during this period, the non standard parts were removed and the original setting of the equipment restored, lubrication, cleaning and inspection checklists had not been introduced into the system and many mechanics and operators had not been trained in the new standards.

\section{CONCLUSION}

From the study, it was concluded that to develop an information system of the company, all intrinsic features of each machine are supposed to be well documented, including machine history with modifications if any are well collated and stored in the machine card. This was well covered under the early equipment maintenance pillar under the TPM pillars. Each of the assemblies and sub-assemblies are to be defined and well coded into the system.

When calculating the performance metrics of a machine, a properly defined productivity model of the same must first be developed. The essence of this is that different machines have different loss types that have to be defined. This can be done through a time study at the shop floor.

In reducing machine breakdowns, a proper systematic way of loss reduction has to be followed as described in Fig 3. The strategy encompasses all aspects of the four Ms, (Man, Machine, Method and Material).

When dealing with man, the strategy has training by utilizing a skill gap analysis (Fig. 12) for both mechanics and operators and defining standard operating procedures for the roles additionally from the root cause analysis, one point lessons are developed to be used as training material.

To reduce time wastage in spare parts management an inventory of all parts was done, and the parts classified according to consumption. A parts catalogue was developed 
showing pictures for the most confusing parts with their bin numbers in the store ( Fig 6).

Main Outputs from the Productivity model are Standard reports, the reports from the data collected could be generated shiftly, daily, weekly, monthly and yearly. The reports include: OEE report, Waste report, Engineering loss report, breakdown recurrence report, team reports and others. The variation of the report depends on the query sent to the dbase. The production of these reports aids in team management and encourages competition between teams.

\section{ACKNOWLEDGEMENTS}

The author greatly appreciates the support of Moi University, Kenya and Wrigley East Africa Company.

\section{REFERENCES}

[1] Alavi, S. (2003, June). Leaning the right way. Retrieved from www.researchgate.net.

[2] Chan, F. T. (2005). Implementation of total productive maintenance: A case study. International Journal of Production Economics, 95(1), pp. 71-94.

[3] Dankbaar, B. (1997). Lean production: denial, confirmation or extension of sociotechnical systems design? Human Relations, 50 pp. 567-583.

[4] Eti, M. C. (2004). Implementing total productive maintenance in Nigerian manufacturing industries. Applied Energy, 79(1), pp.385401

[5] Friedli, T. G. (2010). Analysis of the Implementation of Total Productive Maintenance, Total Quality Management, and Just-InTime in Pharmaceutical Manufacturing. Journal of Pharmacy Innovation, 5(1), pp. 181-192.

[6] Ireland, F. a. (2001). A study of total productive maintenance implementation. Journal of Quality in Maintenance Engineering, 7(3), pp. 183-191.

[7] James P Womack, D. T. (1990). The Machine That Changed The World: The Story of Lean Production.

[8] JIPM Solutions Co. Ltd. (2009). JIPM Solutions. Retrieved 2019 from What Is TPM: www.tpm.jipms.jp/tpm/index.html

[9] Kamran Shahanaghi, S. A. (2009). Analyzing the effects of implementation of Total Productive Maintenance. World Journal of Modelling and Simulation, 120-129.

[10] Nakajima, S. (1995). Management of Production Systems:(TPM). Ney York: Campus Press.

[11] Ottosson, D. (2009). The initiation of Total Productive Maintainance to a pilot production line in the German automobile industry. Mphil Thesis. Germany: Lulea University of Technology.

[12] Pomorski, T. R. (2004). Brooks Automation, Inc. Retrieved from Total Productive Maintenance: http://www3.brooks.com/tmp/2110.pdf

[13] Reitz, A. (2008). Lean TPM. Berlin: Moderne Industrie.

[14] Ross, A. and Francis D. (2003). Lean is not enough. IEE Manufacturing Engineer, 82(4), pp. 14-17.

[15] Venkatesh, J. (2009). Reliabilityweb.com. Retrieved from Total Productive Maintenance: http://reliabilityweb.com/index.php/articles/total_productive_mainte nance

[16] Womack, J. and Jones D. T (1994). From lean production to the lean. Harvard Business Review, 72(2), pp. 93-103.

[17] Womack, J. and Jones D.T (2003). Lean Thinking: Banish Waste and create wealth in your corporation. London: Free Press Business.

[18] Womack, J. P. (1996). Lean Thinking: Banish Waste and Create Wealth in your Corporation. New York: Simon and Schuster Publications. 